Argonne

ANL-ART-121

Report on SNL RCBC Control Options

Nuclear Engineering Division 


\begin{abstract}
About Argonne National Laboratory
Argonne is a U.S. Department of Energy laboratory managed by UChicago Argonne, LLC under contract DE-AC02-06CH11357. The Laboratory's main facility is outside Chicago, at 9700 South Cass Avenue, Argonne, Illinois 60439. For information about Argonne and its pioneering science and technology programs, see www.anl.gov.
\end{abstract}

\begin{abstract}
Disclaimer
This report was prepared as an account of work sponsored by an agency of the United States Government. Neither the United States Government nor any agency thereof, nor UChicago Argonne, LLC, nor any of their employees or officers, makes any warranty, express or implied, or assumes any legal liability or responsibility for the accuracy, completeness, or usefulness of any information, apparatus, product, or process disclosed, or represents that its use would not infringe privately owned rights. Reference herein to any specific commercial product, process, or service by trade name, trademark, manufacturer, or otherwise, does not necessarily constitute or imply its endorsement, recommendation, or favoring by the United States Government or any agency thereof. The views and opinions of document authors expressed herein do not necessarily state or reflect those of the United States Government or any agency thereof, Argonne National Laboratory, or UChicago Argonne, LLC.
\end{abstract}




\section{Report on SNL RCBC Control Options}

prepared by

R. Ponciroli and R. B. Vilim

Nuclear Engineering Division, Argonne National Laboratory

September 30, 2017 





\section{ABSTRACT}

The attractive performance of the $\mathrm{S}-\mathrm{CO}_{2}$ recompression cycle arises from the thermo-physical properties of carbon dioxide near the critical point. However, to ensure efficient operation of the cycle near the critical point, precise control of the heat removal rate by the Printed Circuit Heat Exchanger (PCHE) upstream of the main compressor is required. Accomplishing this task is not trivial because of the large variations in fluid properties with respect to temperature and pressure near the critical point. The use of a model-based approach for the design of a robust feedback regulator is being investigated to achieve acceptable control of heat removal rate at different operating conditions. A first step in this procedure is the development of a dynamic model of the heat exchanger. In this work, a one-dimensional (1-D) control-oriented model of the PCHE was developed using the General Plant Analyzer and System Simulator (GPASS) code. GPASS is a transient simulation code that supports analysis and control of power conversion cycles based on the S- $\mathrm{CO}_{2}$ Brayton cycle. This modeling capability was used this fiscal year to analyze experiment data obtained from the heat exchanger in the SNL recompression Brayton cycle. The analysis suggested that the error in the water flowrate measurement was greater than required for achieving precise control of heat removal rate. Accordingly, a new water flowmeter was installed, significantly improving the quality of the measurement. Comparison of heat exchanger measurements in subsequent experiments with code simulations yielded good agreement establishing a reliable basis for the use of the GPASS PCHE model for future development of a model-based feedback controller. 


\section{Table of Contents}

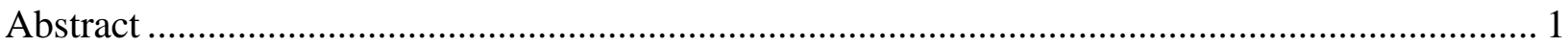

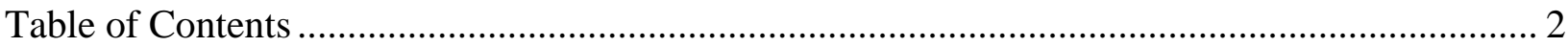

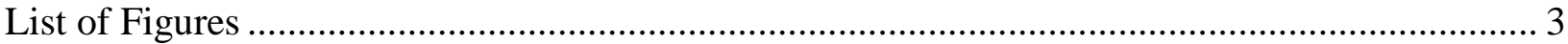

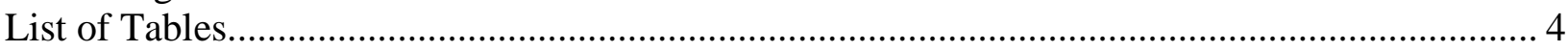

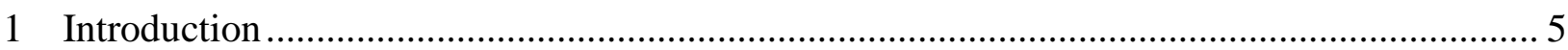

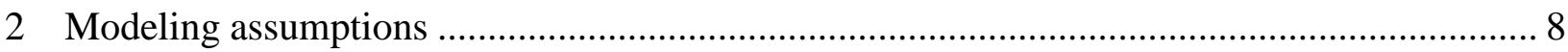

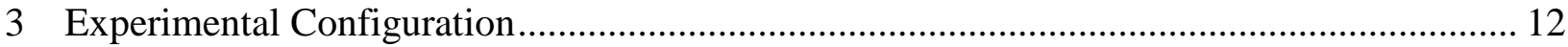

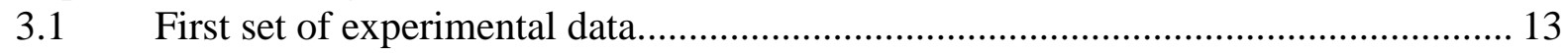

Second set of experimental data ....................................................................... 16

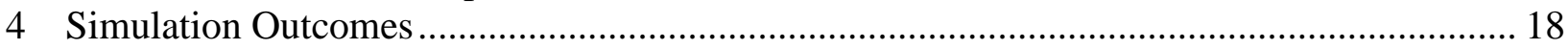

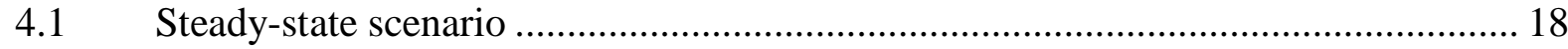

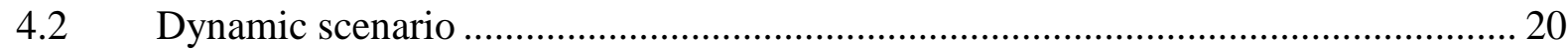

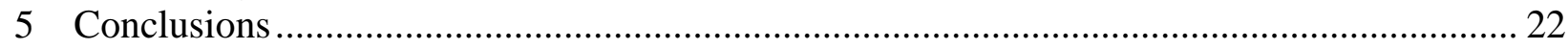

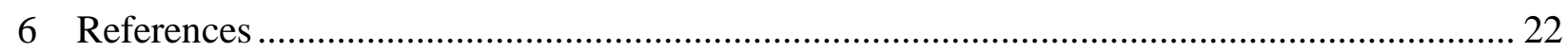




\section{LIST OF FIGURES}

Figure 1. Layout of the $\mathrm{S}-\mathrm{CO}_{2}$ recompression cycle................................................................. 5

Figure 2. Graphical representation of the dependence of the $\mathrm{S}-\mathrm{CO}_{2}$ density as function of

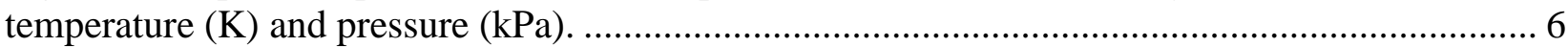

Figure 3. Face of a Printed Circuit Heat Exchanger [3]........................................................... 8

Figure 4. Experimental layout. The adopted temperature (T), pressure (p) and flow rate (F)

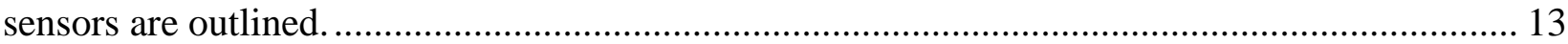

Figure 5. Measured S-CO ${ }_{2}$ temperature at the PCHE inlet (red) and outlet (blue).......................... 13

Figure 6. Measured water temperature at the PCHE inlet (blue) and outlet (red) ......................... 14

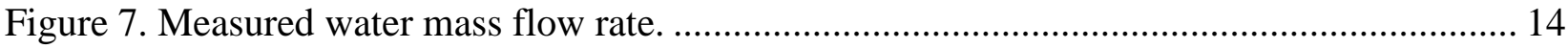

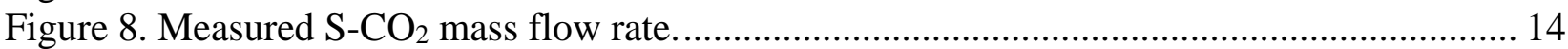

Figure 9. Measured S-CO $\mathrm{CO}_{2}$ pressure at the PCHE inlet (red) and outlet (blue). ............................. 15

Figure 10. Measured S-CO $\mathrm{CO}_{2}$ temperature at the PCHE inlet (red) and outlet (blue)....................... 16

Figure 11. Measured water temperature at the PCHE inlet (blue) and outlet (red). ........................ 16

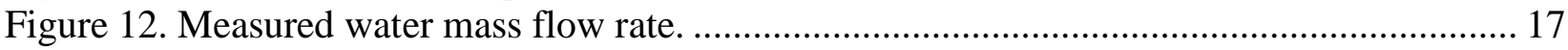

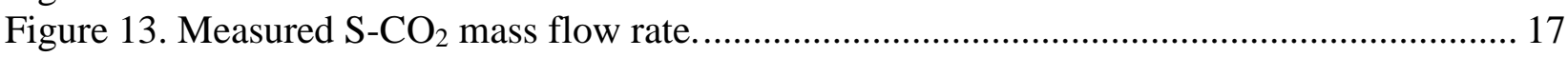

Figure 14. Measured S-CO $\mathrm{CO}_{2}$ pressure at the PCHE inlet (red) and outlet (blue). .......................... 17

Figure 15. Model versus experiment: $\mathrm{S}-\mathrm{CO}_{2}$ temperature at the PCHE inlet (red) and

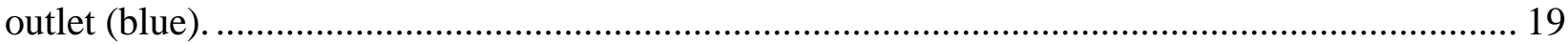

Figure 16. Model versus experiment: Water temperature at the PCHE inlet (blue) and

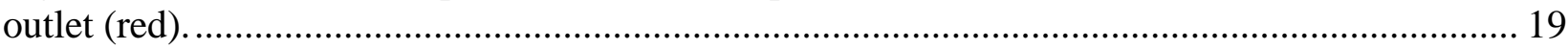

Figure 17. Model versus experiment: Mass flow rates. ................................................................ 19

Figure 18. Thermal power exchange.................................................................................... 20

Figure 19. Evolution of $\mathrm{S}^{-\mathrm{CO}_{2}}$ and water flow rates at the PCHE inlet and outlet....................... 21

Figure 20. Evolution of S-CO $\mathrm{CO}_{2}$ pressures at the PCHE inlet and outlet..................................... 21

Figure 21. Evolution of $\mathrm{S}^{-\mathrm{CO}_{2}}$ temperatures at the PCHE inlet and outlet................................... 21

Figure 22. Evolution of water temperatures at the PCHE inlet and outlet...................................... 22 


\section{LIST OF TABLES}

Table 1. Definition of symbols used in Eqs. (1)-(11)........................................................... 11

Table 2. Definition of subscripts and superscripts used in Eqs. (1)-(11).................................. 11

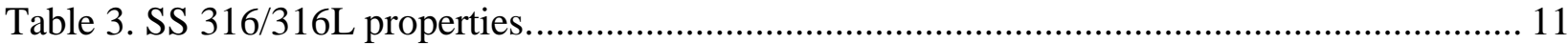

Table 4. PCHE geometrical data provided as input to GPASS code......................................... 12

Table 5. First set of experimental data - Identified initial conditions. ....................................... 15

Table 6. Second set of experimental data - Identified initial conditions................................... 18 


\section{Introduction}

The S-CO $\mathrm{CO}_{2}$ Recompression Closed Brayton Cycle's advantageous performance is greatly enhanced by using high efficiency, yet compact, heat exchangers in the form of Printed Circuit Heat Exchangers (PCHEs) [1]. In particular, the efficiency gains calculated for the $\mathrm{S}-\mathrm{CO}_{2}$ cycle are significant if advantage can be taken of the changes in the carbon dioxide thermo-physical properties near the critical point. An increase in efficiency is achieved when the main cycle compressor operates just above the critical point where the sharp increase in density with pressure minimizes compression work. From this standpoint, the $\mathrm{S}-\mathrm{CO}_{2}$ cooling system plays a fundamental role since its task is to regulate precisely the minimum temperature in the cycle, i.e. the $\mathrm{S}-\mathrm{CO}_{2}$ temperature at the main compressor at its first stage inlet, at different operating conditions. In Figure 1, the layout of the energy conversion cycle is represented, and the pre-cooler (i.e., the single cooler where heat is rejected from the cycle) is outlined.

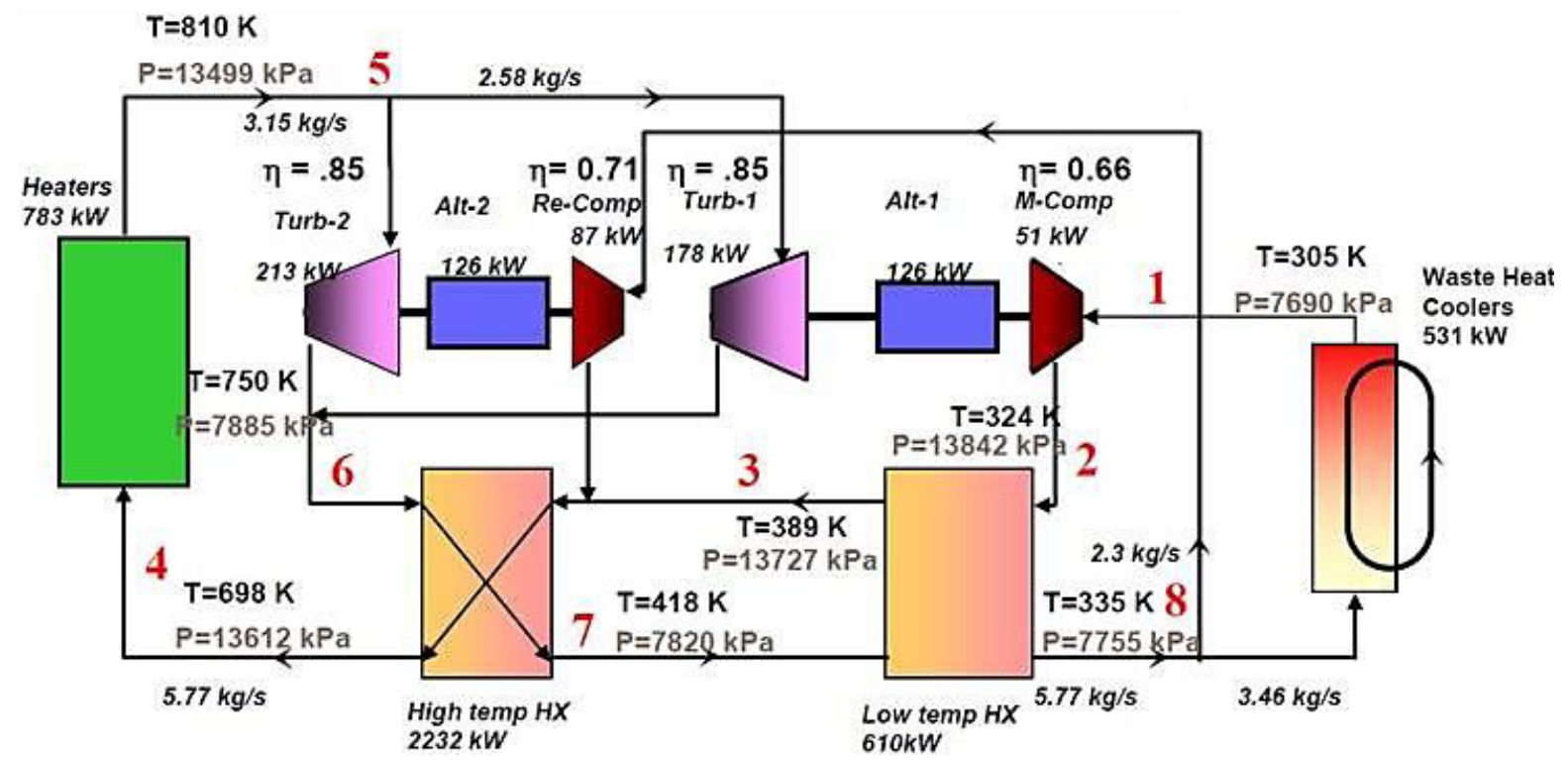

Figure 1. Layout of the $\mathrm{S}-\mathrm{CO}_{2}$ recompression cycle.

In the event the minimum cycle temperature and pressure were to decrease below the critical values, the onset of two-phase flow might degrade compressor performance and potentially cause damage to the compressor blades. On the other hand, the increase of the main compressor inlet temperature by few degrees will markedly change the working fluid density, increasing the compression work and affecting the cycle efficiency. For these reasons, the effective monitoring and control of the compressor inlet temperature is fundamental to ensure a safe and efficient operation of the $\mathrm{S}-\mathrm{CO}_{2}$ recompression cycle. Unfortunately, accomplishing this task is not trivial because of the large variations in fluid properties with respect to temperature and pressure conditions, as shown in Figure 2. Since density and specific heat capacity cannot be determined within a few percent, a feedback controller that can effectively deal with uncertainties affecting the system parameters and 
the sensor measurements is required. In addition, sensors age-related degradation mechanisms might cause calibration drift and response time increase [2], which should be accounted for.

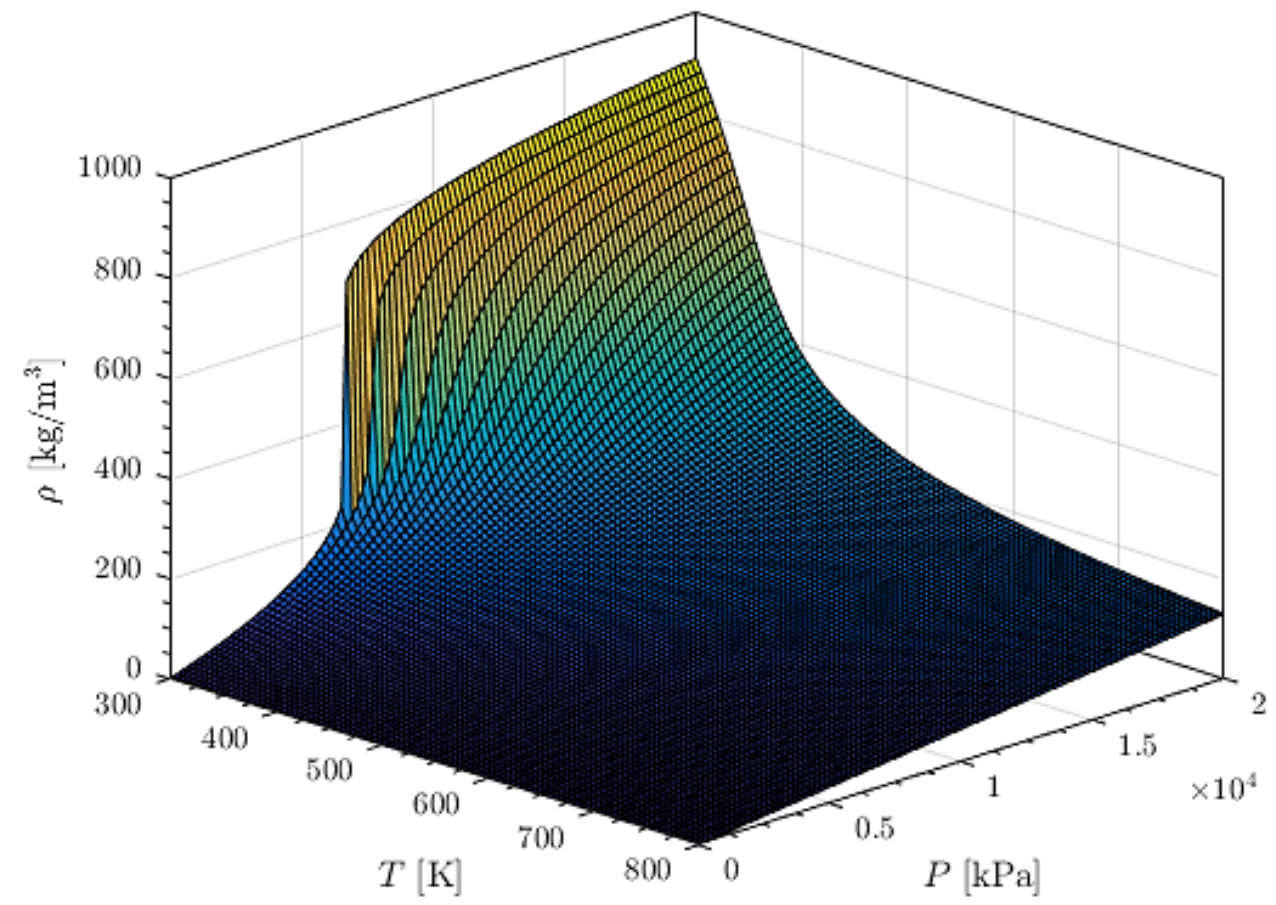

Figure 2. Graphical representation of the dependence of the $\mathrm{S}-\mathrm{CO}_{2}$ density as function of temperature $(\mathrm{K})$ and pressure $(\mathrm{kPa})$.

To address these issues, accurate characterization of the system governing dynamics can be used to design a controller to compensate for the limited accuracy of the measurements of the process variables near the critical point. Accordingly, a model-based approach for the design of a feedback regulator that will ensure good performance at different operating conditions is proposed. The successive stages of this approach are defined here:

\section{(1) Pre-cooler Dynamics Characterization}

Since the $\mathrm{S}-\mathrm{CO}_{2}$ recompression cycle is expected to be operated over a wide range of conditions, the pre-cooler heat disposal capabilities will need to be promptly adjusted according to the instantaneous inlet conditions of the working fluid. Therefore, a dynamic model of the studied physical system which allows simulating the component flexible operation is necessary. Unfortunately, while the large carbon dioxide property variations allow high efficiency, they also complicate standard analysis assumptions [3]. Because of the peculiar features of the adopted pre-cooler, a lumped-parameter model is not suitable, i.e. the geometry of the PCHE requires a more accurate spatial description. Finally, because of the strong dependence of the $\mathrm{S}-\mathrm{CO}_{2}$ thermo-physical properties from temperature and pressure, the model will need to allow evaluating state dependent properties and axial nodalization within component models to account for the non-linear system dynamics. To meet these requirements, a one-dimensional control-oriented model of the PCHE was developed by 
adopting the General Plant Analyzer and System Simulator (GPASS) code [4]. Originally developed to study and compare the dynamic behavior of different configurations of helium closed-loop Brayton cycles, GPASS is a transient simulation control design and cycle scoping code whose modeling capabilities and the solution scheme were upgraded to support analysis of power conversion cycles based on the $\mathrm{S}-\mathrm{CO}_{2}$ Brayton cycle. GPASS uses a onedimensional with perfect mixing solution process that appropriately conserves mass and energy but uses quasi-static momentum conservation. Using this simplification of the momentum equation avoids combining plant phenomena which exist on very different timescales. In this way, the system is prevented from turning numerically stiff. GPASS is modular and flexible, allowing any number of system components. The set of defined components form a system of non-linear equations which, along with the appropriate boundary conditions, is fed to a non-linear system of equations solver [3].

\section{(2) Model-based Design of Pre-cooler Feedback controller}

Once the system dynamics is characterized, the sensitivity of the controlled variable (i.e. the PCHE outlet/compressor inlet temperature) to the perturbations imposed to the system boundary conditions (i.e. inlet water conditions) will be evaluated. In this way, by selecting the most effective variable to regulate the controlled variable evolution, a suitable Single Input Single Output (SISO) control strategy will be defined. At this point, the design of the corresponding Proportional-Integral (PI) controller will be performed by relying on the developed PCHE model. Starting from the dynamic simulation outcomes, the transfer function describing the impact of the control variable on the controlled process variable will be obtained. Indeed, the derivation of the transfer function is crucial to design a robust feedback controller. The regulator parameters will be tuned to ensure the feedback loop suitable values for the phase margin and the cut-off frequency. In this way, the desired dynamic performance can be accomplished while providing at the same time the needed robustness with respect to modeling uncertainties and time delays. Thanks to the proposed model-based approach, it is possible to rely on the Bode theorem, i.e. the robust asymptotic stability of the designed feedback loop can be assessed by satisfying the corresponding hypotheses.

\section{(3) Assessment of Controller Robustness at Perturbed Operating Conditions}

Once designed, the PI controller which implements the defined control strategy, its capabilities need to be assessed by simulating a wide range of operating conditions. First, it will be tested at nominal conditions. In particular, the performance of the regulator will be evaluated in terms of the settling time and the amplitude of the overshoots during the dynamic transients. Eventually, the regulator capabilities need to be assessed at perturbed operating conditions as well, i.e. the controller is expected to ensure the same performance at different power levels. In particular, the robustness of the PI controller against time delays and sensor uncertainties needs to be assessed.

(4) Investigation of Advanced Control Schemes 
If the performance of the designed PI controller is not acceptable, the adoption of advanced control schemes will be investigated. The main issues might be associated with a narrow range of operability of the designed regulator. In particular, besides the fact that the PI controller is based on a linear scheme, the tuning is based on the derived transfer function, i.e. the features of the designed regulator are optimized with respect to the nominal conditions, but there may be significant deviation from this assumption because of the inherent non-linear dynamics. Other concerns might be due to the sensitivity of the regulator performance to the uncertainties affecting the measurements. From this standpoint, the adoption of advanced control approaches, such as model-based predictive control (MPC) coupled with an extended Kalman filter, might address many of these issues by implementing a robust model-based scheme, which inherently accounts for the time-delays. In addition, this approach would allow implementing multiple input, multiple output (MIMO) control strategies, i.e. the operation of the different actuators could be suitably synchronized to achieve the desired power variations by limiting the perturbations induced on the component operating conditions.

\section{Modeling assumptions}

A PCHE is created by chemically etching small semi-circular channels into a thin metal plate. Alternating hot and cold fluid plates are arranged in a counter flow fashion and then diffusion bonded together to create a solid block of metal with many channels. Besides having a large heat transfer area per unit volume, a PCHE is robust, allowing large pressure and temperature differences that could require significant design changes in other types of heat exchangers [3].

[Figure withheld. Inquiries should be directed to the author]

Figure 3. Face of a Printed Circuit Heat Exchanger [3].

By taking advantage of the regularity in a PCHE's channels (Figure 3) and by assuming it to be adiabatic to the environment (i.e. the hot fluid only loses heat from internal surface convection), the modeling of the PCHE can be greatly simplified. In particular, a few simplifying assumptions [3] were made:

(1) The total mass flow rate is uniformly distributed among the channels.

(2) The temperature distribution in the heat exchanger is periodic with the period of two plates (one hot and one cold).

(3) Hot and cold side channel and plate geometry is the same.

(4) The wall channel temperature is uniform along channel periphery at every axial location.

(5) The heat conduction area is assumed to be equal to the heat transfer area in the channel.

(6) The heat conduction length is equal to the distance between the hot and cold channel.

(7) The presence of two cross-flow regions, on each end of the PCHE is neglected.

Therefore, since the hot and cold side geometry is the same and knowing that there is a one-to-one correspondence between hot and cold channels, the whole PCHE might be reduced to single hot 
and cold channels [5]. The channels of the actual PCHE are semicircular wavy channels. The passage flow area and the corresponding equivalent hydraulic diameter are calculated accordingly

$$
\begin{gathered}
A_{p}=\frac{\pi\left(\frac{d_{c}^{2}}{4}\right)}{2} \\
d_{e q}=\frac{4 \pi d_{c}^{2}}{8\left(\pi \frac{d_{c}}{2}+d_{c}\right)}
\end{gathered}
$$

The total heat exchanger performance can be calculated based on the performance of one hot and one cold channel by simply multiplying by the number of channels in the heat exchanger. These single channels can be modelled with a 1-D code by assuming that the conditions within a channel are uniform at any given distance into the PCHE. In the 1-D discretization, the PCHE is axially divided into small sections. By using small enough sections one may assume that properties are constant (within a section) and it becomes relatively simple to converge to a solution [3]. Below are the equations that are solved at each axial zone. The mass conservation equations for the hot and cold side fluid yield, respectively

$$
\begin{aligned}
& \mathrm{m}_{\text {hot }}^{p+1}=\mathrm{m}_{\text {hot-in }}^{p+1}-\frac{V_{\text {hot }}\left(\rho_{\text {hot }}^{p+1}-\rho_{\text {hot }}^{p}\right)}{2 \Delta t} \\
& \mathrm{~m}_{\text {cold }}^{p+1}=\mathrm{m}_{\text {cold-in }}^{p+1}+\frac{V_{\text {cold }}\left(\rho_{\text {cold }}^{p+1}-\rho_{\text {cold }}^{p}\right)}{2 \Delta t}
\end{aligned}
$$

The wall separating the hot and cold streams is represented by a single thermal node. The wall temperature is given by

$$
\mathrm{T}_{\text {wall }}^{p+1}=\frac{h t c_{\text {hot }}^{p+1} A \mathrm{~T}_{\text {hot }}^{p+1}+h t c_{\text {cold }}^{p+1} A \mathrm{~T}_{\text {cold }}^{p+1}+\frac{M_{\text {wall }} C_{\text {wall }}}{\Delta t} \mathrm{~T}_{\text {wall }}^{p}}{h t c_{\text {hot }}^{p+1} A+h t c_{\text {cold }}^{p+1} A+\frac{M_{\text {wall }} C_{\text {wall }}}{\Delta t}}
$$

The quasi-static momentum equation is solved for the hot and cold fluids within a zone. The fluid pressure drop is given by the frictional component, which can be calculated by adopting dedicated correlations. Therefore, for the hot side fluid, the outlet pressure is given by

$$
\mathrm{P}_{\text {hot }}^{p+1}=\frac{\mathrm{P}_{\text {hot-in }}^{p+1}+\left(\mathrm{P}_{\text {hot-in }}^{p+1}-\Delta \mathrm{P}_{\text {hot }}^{p+1}\right)}{2}
$$

and for the cold side by 


$$
\mathrm{P}_{\text {cold }}^{p+1}=\frac{\mathrm{P}_{\text {cold-in }}^{p+1}+\left(\mathrm{P}_{\text {cold-in }}^{p+1}-\Delta \mathrm{P}_{\text {cold }}^{p+1}\right)}{2}
$$

The energy conservation equations for the hot and cold side fluid yield, respectively

$$
\begin{aligned}
\mathrm{h}_{\text {hot }}^{p+1} & =\frac{m_{\text {hot-in }}^{p+1} \mathrm{~h}_{\text {hot-in }}^{p+1}-h t c_{\text {hot }}^{p+1} A\left(\mathrm{~T}_{\text {hot }}^{p+1}-\mathrm{T}_{\text {wall }}^{p+1}\right)-\frac{V_{h o t}\left(\rho_{\text {hot }}^{p+1} u_{h o t}^{p+1}-\rho_{\text {hot }}^{p} u_{\text {hot }}^{p+1}\right)}{\Delta t}}{2 m_{\text {hot }- \text { out }}^{p+1}} \\
& +\frac{h_{\text {hot-in }}^{p+1}}{2}
\end{aligned}
$$

and

$$
\begin{aligned}
\mathrm{h}_{\text {cold }}^{p+1} & =\frac{m_{\text {cold-in }}^{p+1} \mathrm{~h}_{\text {cold-in }}^{p+1}-h t c_{\text {cold }}^{p+1} A\left(\mathrm{~T}_{\text {wall }}^{p+1}-\mathrm{T}_{\text {cold }}^{p+1}\right)+\frac{V_{\text {cold }}\left(\rho_{\text {cold }}^{p+1} u_{\text {cold }}^{p+1}-\rho_{\text {cold }}^{p} u_{\text {cold }}^{p+1}\right)}{\Delta t}}{2 m_{\text {cold }- \text { out }}^{p+1}} \\
& +\frac{h_{\text {cold-in }}^{p+1}}{2}
\end{aligned}
$$

As for the evaluation of the heat disposal capabilities, at this preliminary stage, the channels will be assumed to be straight. This assumption is conservative as wavy channels improve the heat transfer performance significantly. The Gnielinski correlation for the straight semicircular channels [1][6] is used for turbulent flow in water and $\mathrm{CO}_{2}$, since it is simple, experimentally based, and a recommended correlation that includes entrance length effects.

$$
N u=\frac{\frac{f_{c}}{8}(R e-1000) \operatorname{Pr}}{1+12.7\left(\operatorname{Pr}^{\frac{2}{3}}-1\right) \sqrt{\frac{f_{c}}{8}}}
$$

For laminar fluid flow in water and $\mathrm{CO}_{2}$ the Hesselgreaves [7] recommends Eq. (11) for the present conditions.

$$
N u=4.089
$$

In addition, Hesselgreaves recommends a set of tabular data from [8] for the laminar thermal entrance length effect, which is linearly interpolated in practice.

Finally, a transition region is used to create a smooth transition between the laminar and turbulent Nusselt numbers to calculate the heat transfer coefficient. In particular, since the turbulent correlation begin at $R e=2300$, a transition region is chosen to range from $R e=500$ above and below the transition point, i.e. $1800<R e<2800$. In terms of implementation, the smooth transition is created by adopting a linear interpolation. The foregoing assumption of straight channels might be unrealistic for the $\mathrm{CO}_{2}$ side and the water side of a PCHE. The channels might be zigzagged. It is thought to be likely that the channels on the $\mathrm{CO}_{2}$ side are zigzagged. It is also 
likely that there are zigzagged channels on the water side, although it is not inconceivable that the channels could be straight on the water side. A future next step will be to improve the modeling by implementing correlations for heat transfer and pressure drop [9] that are based upon data from Heatric PCHEs.

Table 1. Definition of symbols used in Eqs. (1)-(11).

\begin{tabular}{cl}
\hline Symbol & \multicolumn{1}{c}{ Description } \\
\hline$A$ & Heat transfer area, $\left(\mathrm{m}^{2}\right)$ \\
$\mathrm{A}_{p}$ & Passage flow area, $\left(\mathrm{m}^{2}\right)$ \\
$C$ & Wall specific heat, $(\mathrm{J} / \mathrm{kgK})$ \\
$d_{c}$ & Channel diameter, $(\mathrm{m})$ \\
$d_{e q}$ & Equivalent hydraulic diameter, $(\mathrm{m})$ \\
$h$ & Fluid specific enthalpy, $(\mathrm{J} / \mathrm{kg})$ \\
$h t c$ & Heat transfer coefficient, $\left(\mathrm{W} / \mathrm{m}^{2} \mathrm{~K}\right)$ \\
$m$ & Mass flow rate, $(\mathrm{kg} / \mathrm{s})$ \\
$M$ & Control volume mass, $(\mathrm{kg})$ \\
$N u$ & Nusselt number, $(-)$ \\
$P$ & Pressure, $($ Pa) \\
$\Delta P$ & Pressure drop, $(\mathrm{Pa})$ \\
$P r$ & Prandtl number, $(-)$ \\
$R e$ & Reynolds number, $(-)$ \\
$T$ & Temperature, $(\mathrm{K})$ \\
$u$ & Fluid specific internal energy, $(\mathrm{J} / \mathrm{kg})$ \\
$V$ & Control volume, $\left(\mathrm{m}^{3}\right)$ \\
$\rho$ & Fluid density, $\left(\mathrm{kg} / \mathrm{m}^{3}\right)$ \\
$\Delta t$ & Time step amplitude, $(\mathrm{s})$ \\
\hline &
\end{tabular}

Table 2. Definition of subscripts and superscripts used in Eqs. (1)-(11).

\begin{tabular}{|c|c|}
\hline Symbol & Description \\
\hline cold & Cold side \\
\hline hot & Hot side \\
\hline in & Inlet \\
\hline out & Outlet \\
\hline$p$ & Time index \\
\hline wall & Wall separating the hot and cold streams \\
\hline
\end{tabular}

The thermo-physical properties of the stainless steel are reported Table 3. The parameters needed by the GPASS model are derived and reported in Table 4.

Table 3. SS 316/316L properties.

\begin{tabular}{ll}
\hline Variable & Design value \\
\hline Thermal conductivity & $14.6 \mathrm{~W} / \mathrm{mK}$ \\
\hline
\end{tabular}




\begin{tabular}{ll} 
Density & $7900 \mathrm{~kg} / \mathrm{m}^{3}$ \\
Specific heat capacity & $450 \mathrm{~J} / \mathrm{kgK}$ \\
\hline
\end{tabular}

Table 4. PCHE geometrical data provided as input to GPASS code.

\begin{tabular}{ll}
\hline Variable & Design value \\
\hline Hot channel diameter & $1.86 \mathrm{~mm}$ \\
Cold channel diameter & $1.86 \mathrm{~mm}$ \\
Hot plate thickness & $1.39 \mathrm{~mm}$ \\
Cold plate thickness & $1.39 \mathrm{~mm}$ \\
Hot pitch & $2.39 \mathrm{~mm}$ \\
Cold pitch & $2.39 \mathrm{~mm}$ \\
Plate roughness & $0.1 \mathrm{~mm}$ \\
PCHE height & $0.196 \mathrm{~m}$ \\
PCHE width & $0.267 \mathrm{~m}$ \\
PCHE length & $0.496 \mathrm{~m}$ \\
\hline
\end{tabular}

\section{Experimental Configuration}

In Figure 4, the graphical representation of the experimental layout of the $\mathrm{S}-\mathrm{CO}_{2}$ recompression cycle is displayed. In particular, the main sensors providing the measurements which will assess the dynamic model of the PCHE are outlined. From the standpoint of simulating the governing dynamics of the PCHE and the assessment of the developed model, it is fundamental to rely on accurate measurements of the process variables at the PCHE interfaces, both for the hot and cold sides. In particular, the profiles of flow rate, pressure and temperature evolution at the PCHE inlet are imposed as time-dependent boundary conditions. Conversely, the variables representing the pressure and temperature evolution at the PCHE outlet are adopted to assess the simulation outcomes. In Figure 4, the boundary condition variables are outlined in blue, while the variables to be compared with the experimental data are outlined in red.

$$
\begin{aligned}
& \mathrm{S}-\mathrm{CO}_{2} \text { Boundary Conditions }=\left\{\begin{array}{c}
\text { Inlet Pressure } \\
\text { Inlet Temperature } \\
\text { Flow Rate }
\end{array}\right\} \\
& \text { Water Boundary Conditions }=\left\{\begin{array}{c}
\text { Inlet Temperature } \\
\text { Flow Rate }
\end{array}\right\} \\
& \mathrm{S}-\mathrm{CO}_{2} \text { Benchmark Variables }=\left\{\begin{array}{c}
\text { Outlet Pressure } \\
\text { Outlet Temperature }
\end{array}\right\} \\
& \text { Water Benchmark Variables }=\{\text { Outlet Temperature }\}
\end{aligned}
$$




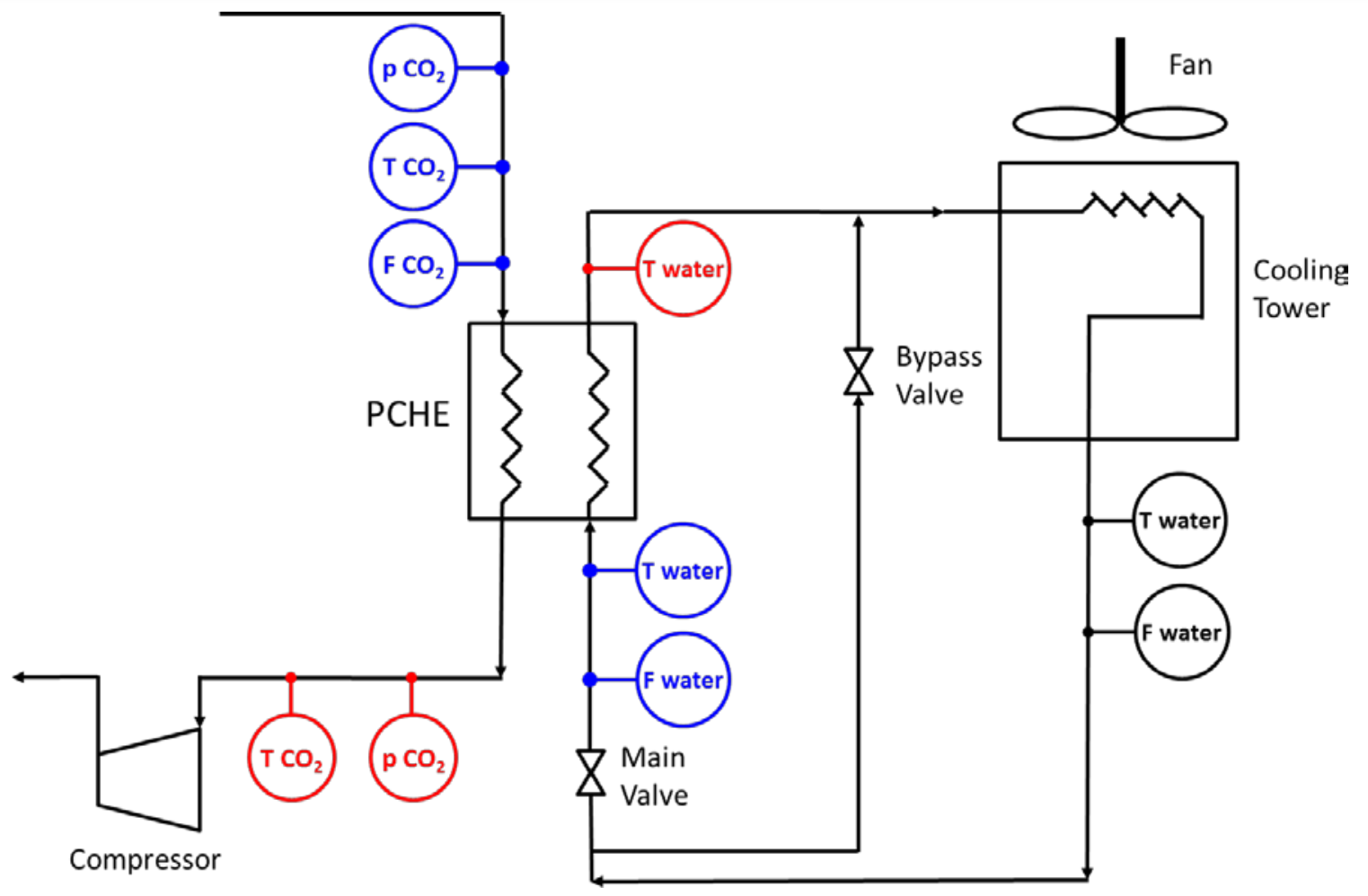

Figure 4. Experimental layout. The adopted temperature (T), pressure (p) and flow rate (F) sensors are outlined.

\subsection{First set of experimental data}

In this section, the first set of experimental data received by ANL is presented. In Figure 5-10, the measured $\mathrm{S}-\mathrm{CO}_{2}$ and the water temperatures, the $\mathrm{S}-\mathrm{CO}_{2}$ and the water flow rates, and the $\mathrm{S}-\mathrm{CO}_{2}$ pressure are presented, respectively.

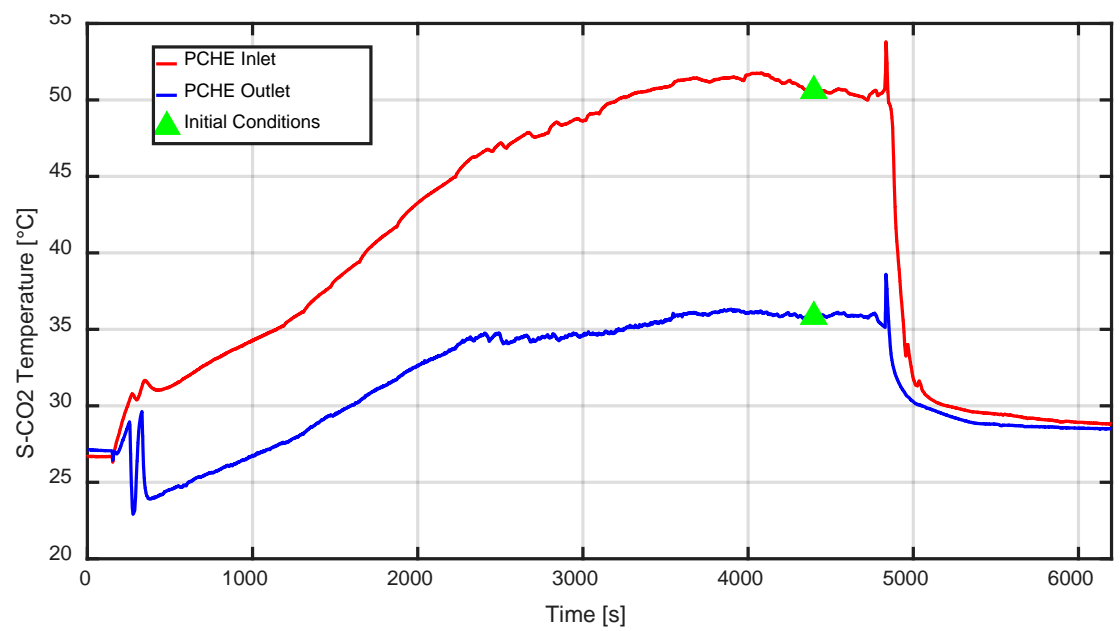

Figure 5. Measured S-CO $\mathrm{CO}_{2}$ temperature at the PCHE inlet (red) and outlet (blue). 


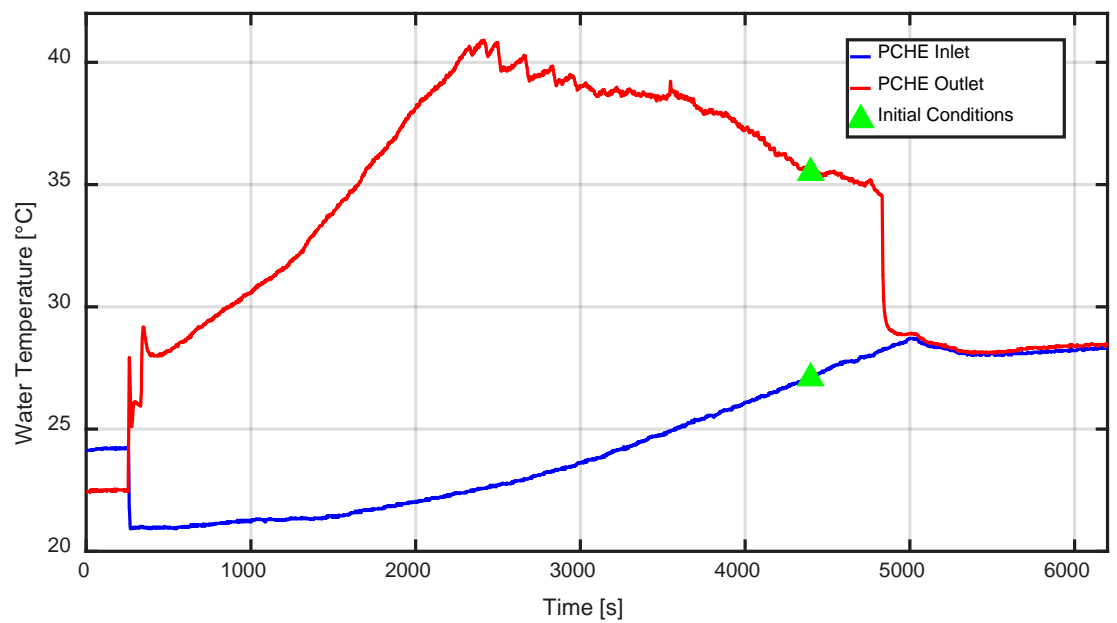

Figure 6. Measured water temperature at the PCHE inlet (blue) and outlet (red).

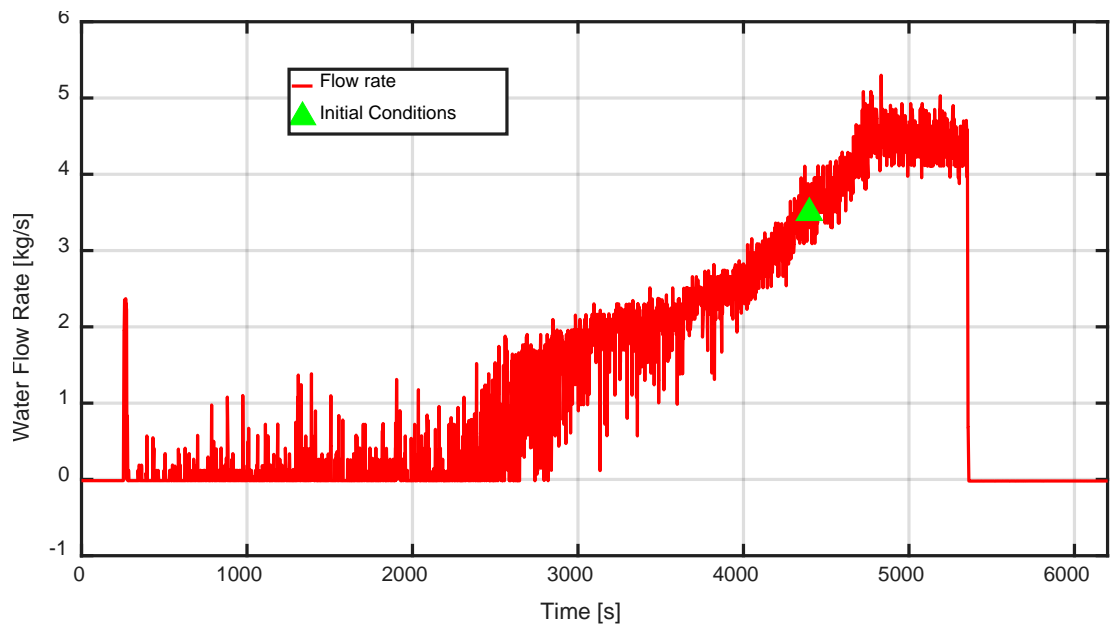

Figure 7. Measured water mass flow rate.

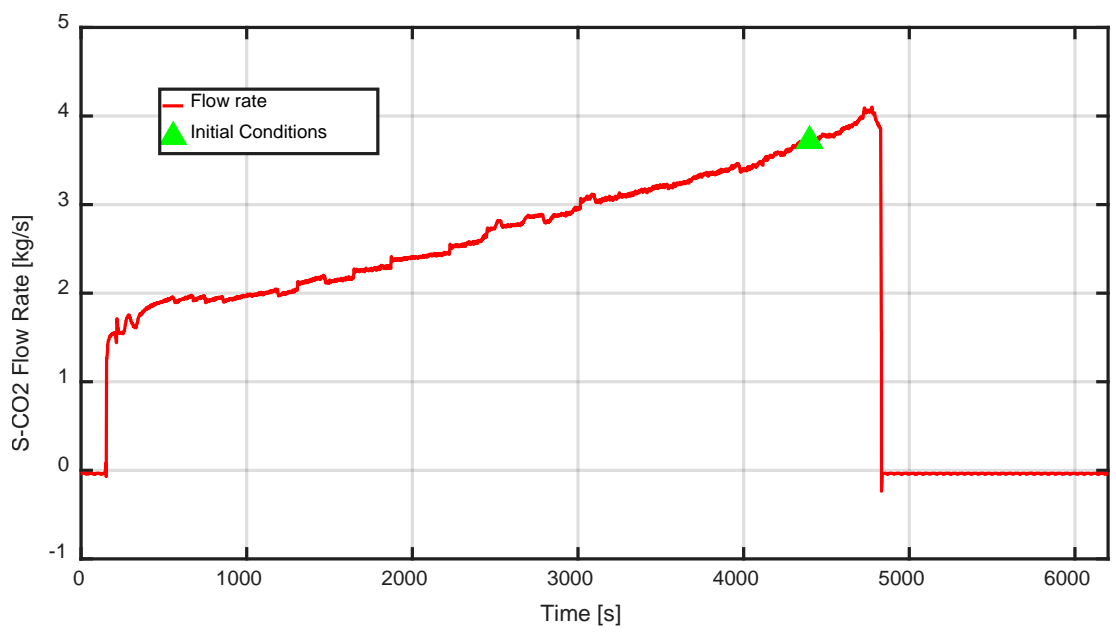

Figure 8. Measured $\mathrm{S}-\mathrm{CO}_{2}$ mass flow rate. 


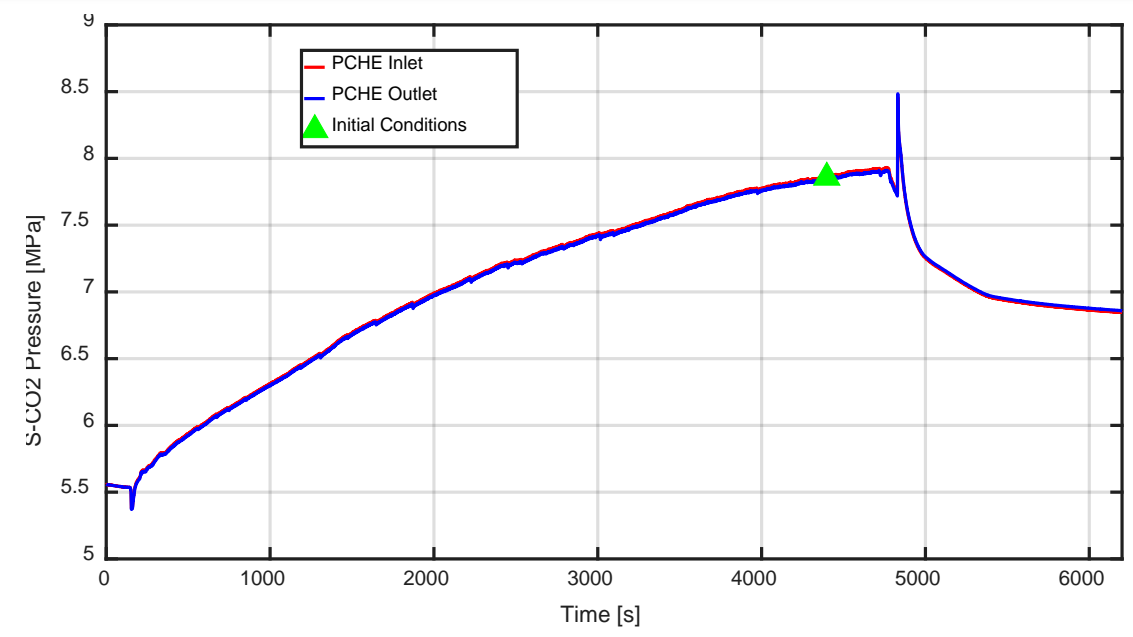

Figure 9. Measured S-CO 2 pressure at the PCHE inlet (red) and outlet (blue).

As a first step in the development of a PCHE model, the operation at steady-state conditions is simulated. By observing the S-CO 2 temperatures, the fluid conditions after 4000 seconds were identified as the initial conditions (IC) to be provided to the component model. The corresponding values for temperatures, pressures, flow rates and enthalpies (represented by green triangles in Figure 5-10) are given in Table 5.

Table 5. First set of experimental data - Identified initial conditions.

\begin{tabular}{ll}
\hline Variable & Steady state value \\
\hline $\mathrm{S}-\mathrm{CO}_{2}$ inlet temperature & $50.58^{\circ} \mathrm{C}$ \\
$\mathrm{S}-\mathrm{CO}_{2}$ outlet temperature & $35.84^{\circ} \mathrm{C}$ \\
Water inlet temperature & $27.09^{\circ} \mathrm{C}$ \\
Water outlet temperature & $35.49^{\circ} \mathrm{C}$ \\
$\mathrm{S}-\mathrm{CO}_{2}$ inlet pressure & $7.856 \mathrm{MPa}$ \\
$\mathrm{S}-\mathrm{CO}_{2}$ outlet pressure & $7.840 \mathrm{MPa}$ \\
$\mathrm{S}-\mathrm{CO}_{2}$ mass flow rate & $3.716 \mathrm{~kg} / \mathrm{s}$ \\
$\mathrm{Water}$ mass flow rate & $3.494 \mathrm{~kg} / \mathrm{s}$ \\
$\mathrm{S}-\mathrm{CO}_{2}$ inlet enthalpy & $440.2 \mathrm{~kJ} / \mathrm{kgK}$ \\
$\mathrm{S}-\mathrm{CO}_{2}$ outlet enthalpy & $382.2 \mathrm{~kJ} / \mathrm{kgK}$ \\
\hline
\end{tabular}

To verify that these operating conditions correspond to a quasi-static equilibrium point, the thermal power exchanged between the two fluids was evaluated (Eqs.(16)-(17)).

$$
\begin{aligned}
& Q_{\text {water }}=\dot{m}_{\text {water }} \cdot c_{\text {water }} \cdot\left(T_{\text {water }}{ }^{\text {out }}-T_{\text {water }}{ }^{\text {in }}\right)=122.717 \mathrm{~kW} \\
& Q_{S-\mathrm{CO}_{2}}=\dot{m}_{\mathrm{S}-\mathrm{CO}_{2}} \cdot\left(h_{S-\mathrm{CO}_{2}}{ }^{\text {in }}-h_{S-\mathrm{CO}_{2}}{ }^{\text {out }}\right)=215.341 \mathrm{~kW}
\end{aligned}
$$

This energy balance show that there is a significant discrepancy between the thermal power that is rejected by the $\mathrm{S}-\mathrm{CO}_{2}$ and that absorbed by the water (the relative difference between the two values 
is equal to 43.01\%). From our understanding, one of the factors causing this discrepancy is the noise affecting the water flow measurement. As shown in Figure 7, the fluctuations in the flowmeter signal can reach the $15-20 \%$ of the measured value. To address this issue, the experiment equipment was modified as described below.

\subsection{Second set of experimental data}

In this section, the second set of experimental data ANL received is presented. In Figure 10-15, the $\mathrm{S}-\mathrm{CO}_{2}$ and the water temperatures, the $\mathrm{S}-\mathrm{CO}_{2}$ and the water flow rates, and the $\mathrm{S}-\mathrm{CO}_{2}$ pressure are represented, respectively. With respect to the previous set of data, the experimental setup was improved. In particular, a new water flow meter, which provides much more accurate readings down to about 3 gallon per minute (gpm), was installed. As shown Figure 12, the new measurements are affected by limited noise contribution and by lower uncertainty.

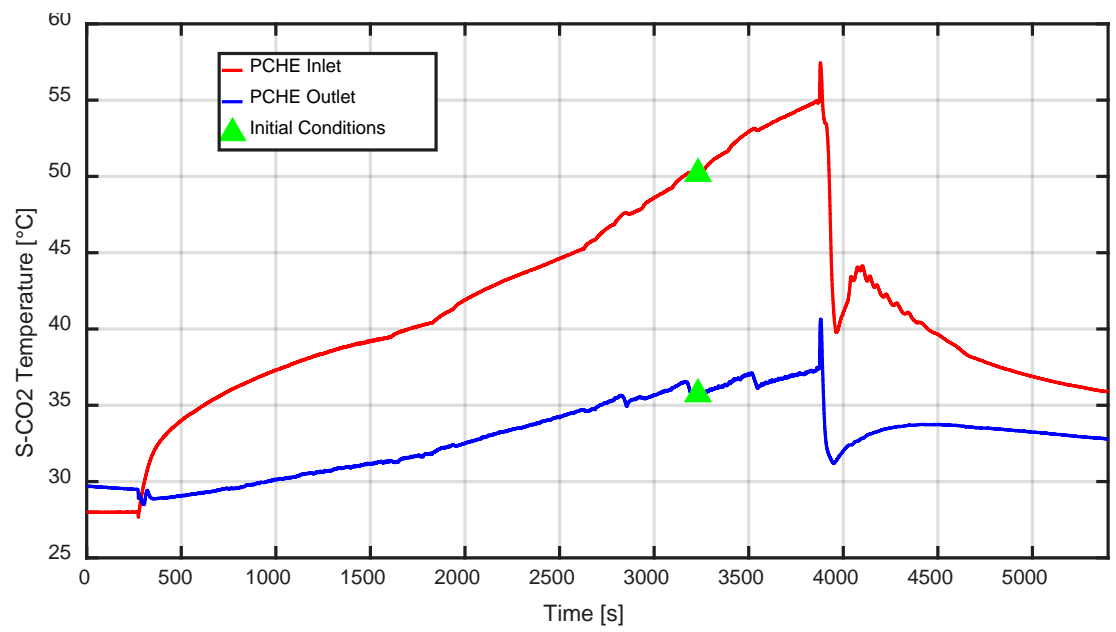

Figure 10. Measured S-CO ${ }_{2}$ temperature at the PCHE inlet (red) and outlet (blue).

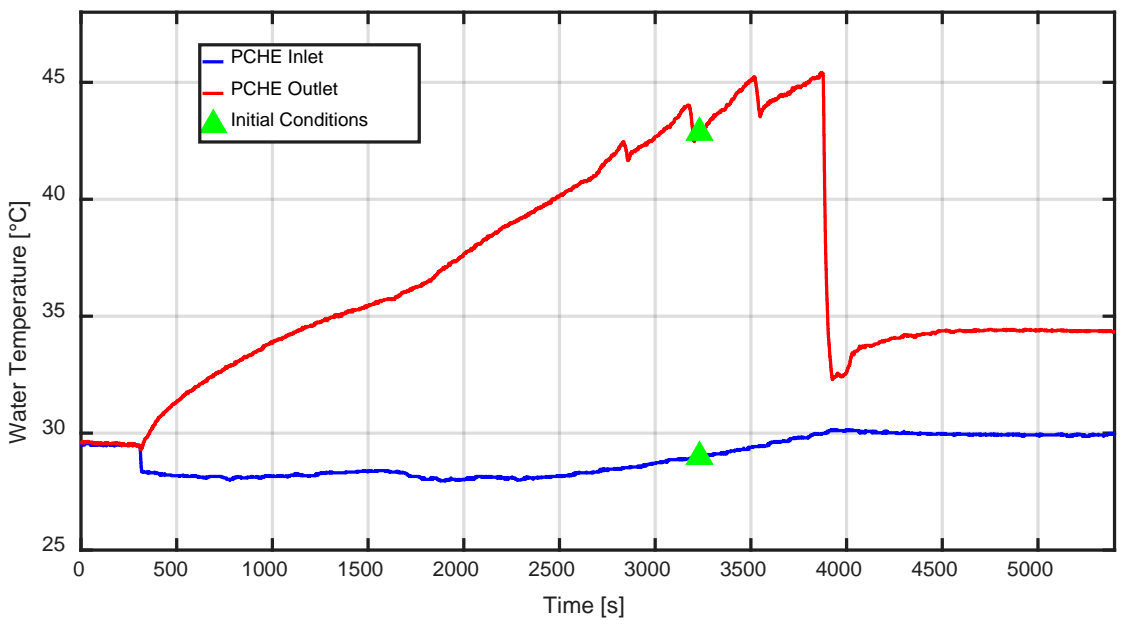

Figure 11. Measured water temperature at the PCHE inlet (blue) and outlet (red). 


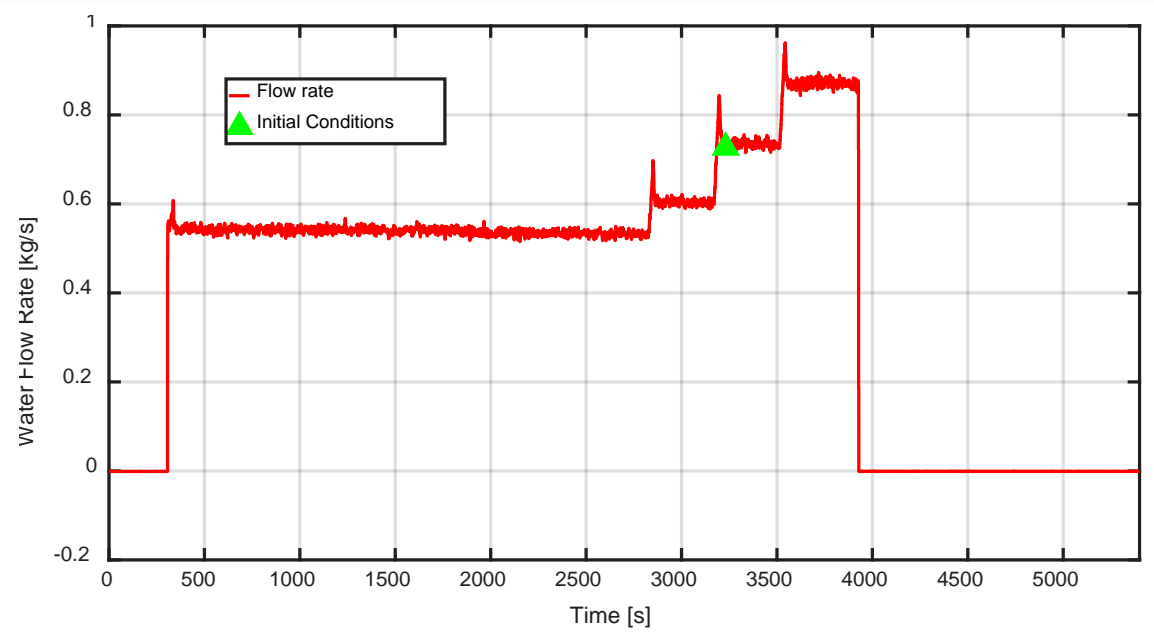

Figure 12. Measured water mass flow rate.

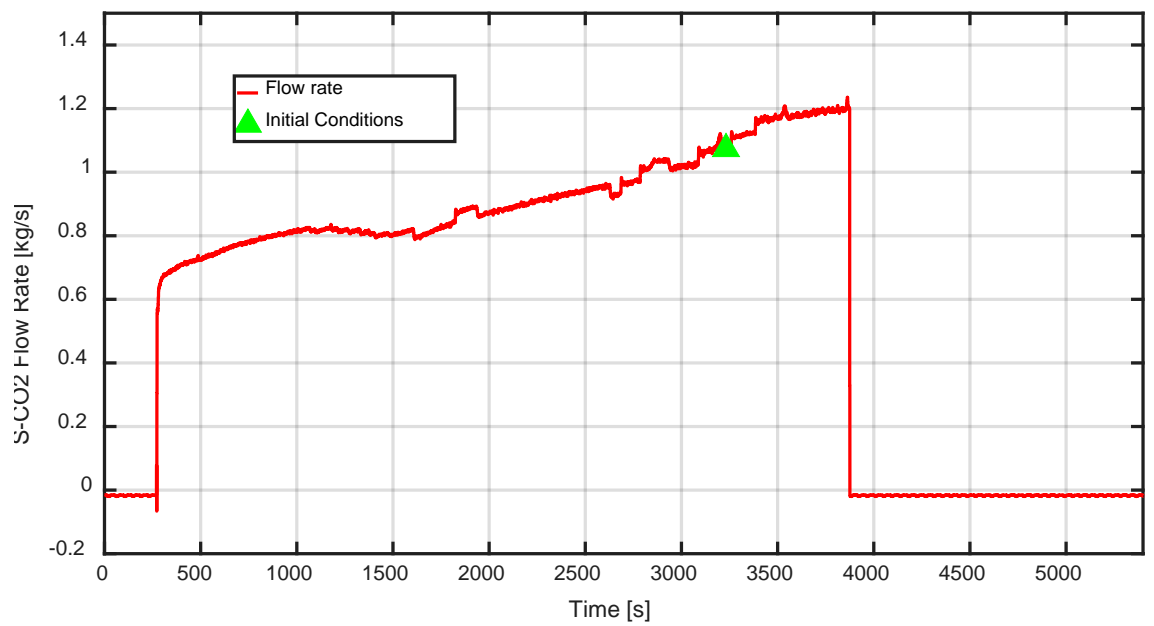

Figure 13. Measured S-CO $\mathrm{CO}_{2}$ mass flow rate.

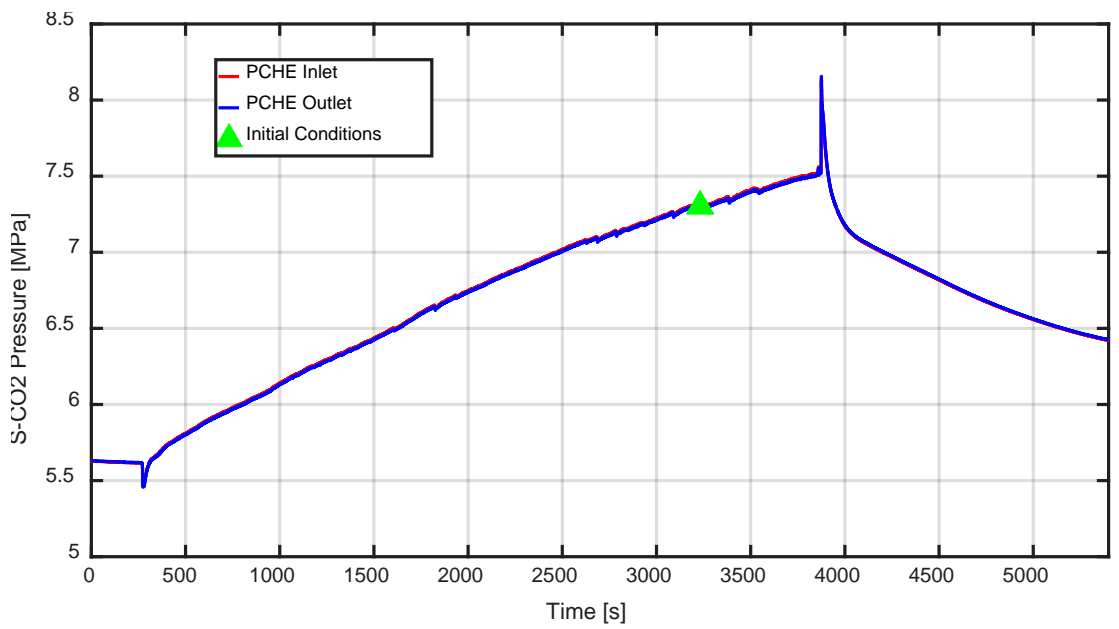

Figure 14. Measured S-CO2 pressure at the PCHE inlet (red) and outlet (blue). 
As shown in Figure 12, the water flow rate was progressively increased by step-wise variations. The fluid conditions after one of these steps were identified as the initial conditions to be provided to the component model. The corresponding values for temperatures, pressures, flow rates and enthalpies (represented by green triangles in Figure 10-15) are given in Table 6.

Table 6. Second set of experimental data - Identified initial conditions.

\begin{tabular}{ll}
\hline Variable & Steady state value \\
\hline $\mathrm{S}-\mathrm{CO}_{2}$ inlet temperature & $50.17^{\circ} \mathrm{C}$ \\
$\mathrm{S}-\mathrm{CO}_{2}$ outlet temperature & $35.71^{\circ} \mathrm{C}$ \\
Water inlet temperature & $28.99^{\circ} \mathrm{C}$ \\
Water outlet temperature & $42.84^{\circ} \mathrm{C}$ \\
$\mathrm{S}-\mathrm{CO}_{2}$ inlet pressure & $7.306 \mathrm{MPa}$ \\
$\mathrm{S}-\mathrm{CO}_{2}$ outlet pressure & $7.299 \mathrm{MPa}$ \\
$\mathrm{S}-\mathrm{CO}_{2}$ mass flow rate & $1.074 \mathrm{~kg} / \mathrm{s}$ \\
$\mathrm{W}$ ater mass flow rate & $0.726 \mathrm{~kg} / \mathrm{s}$ \\
$\mathrm{S}-\mathrm{CO}_{2}$ inlet enthalpy & $449.0 \mathrm{~kJ} / \mathrm{kgK}$ \\
$\mathrm{S}-\mathrm{CO}_{2}$ outlet enthalpy & $409.2 \mathrm{~kJ} / \mathrm{kgK}$ \\
\hline
\end{tabular}

To verify that the identified conditions do refer to a quasi-static equilibrium point, once again, the thermal power exchanged between the two fluids was evaluated (Eqs. (18)(19)).

$$
\begin{aligned}
& Q_{\text {water }}=\dot{m}_{\text {water }} \cdot c p_{\text {water }} \cdot\left(T_{\text {water }}{ }^{\text {out }}-T_{\text {water }}{ }^{\text {in }}\right)=42.017 \mathrm{~kW} \\
& Q_{S-\mathrm{CO}_{2}}=\dot{m}_{{\mathrm{S}-\mathrm{CO}_{2}}} \cdot\left({h_{S-\mathrm{CO}_{2}}}^{\text {in }}-{h_{S-\mathrm{CO}_{2}}}^{\text {out }}\right)=42.773 \mathrm{~kW}
\end{aligned}
$$

This energy balance shows that the value of the thermal power disposed by the $\mathrm{S}-\mathrm{CO}_{2}$ is very close to the one absorbed by the water. This result confirms the choice of adopting this point as quasistatic operating conditions for the component.

\section{Simulation Outcomes}

\subsection{Steady-state scenario}

To proceed with GPASS modeling, it is necessary to define the physical system boundary conditions. In particular, the identified quasi-static values for the $\mathrm{S}-\mathrm{CO}_{2}$ inlet temperature, inlet pressure and flow rate, and the water inlet temperature and flow rate are imposed as steady state boundary conditions. A comparison of model predictions (solid lines) with the collected measurements (dash lines) appears in Figure 15-18, showing a good agreement. 


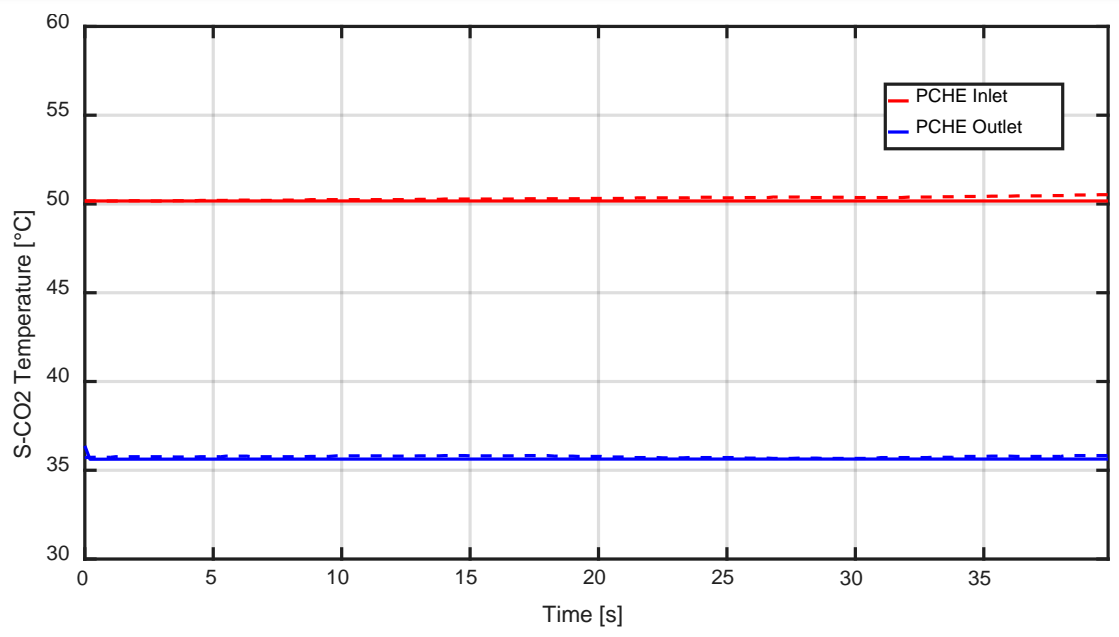

Figure 15. Model versus experiment: S-CO $\mathrm{CO}_{2}$ temperature at the PCHE inlet (red) and outlet (blue).

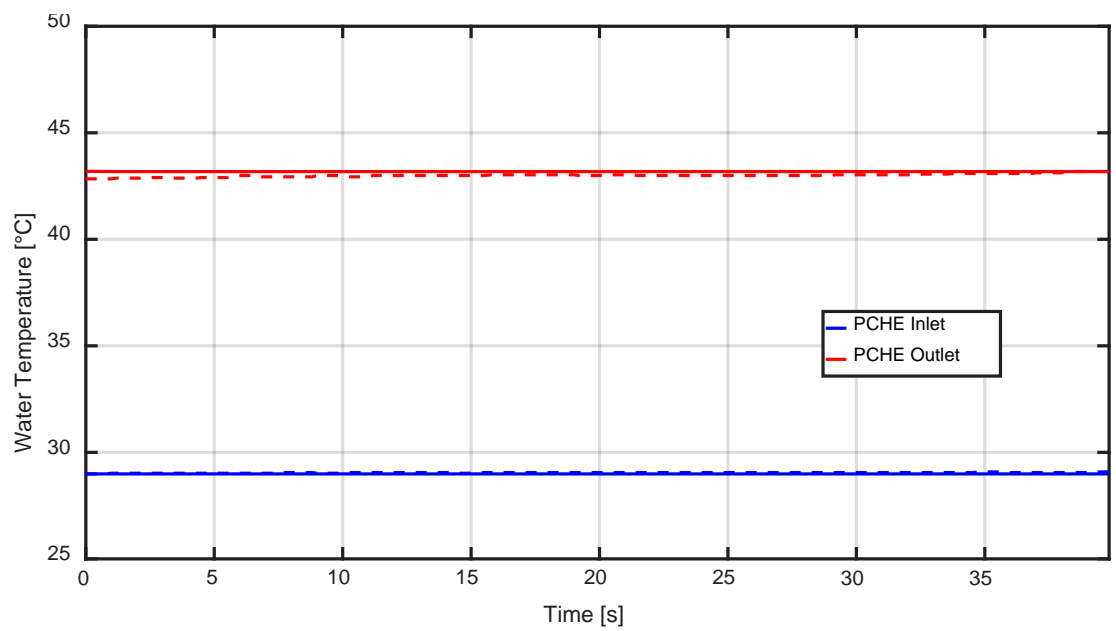

Figure 16. Model versus experiment: Water temperature at the PCHE inlet (blue) and outlet (red).

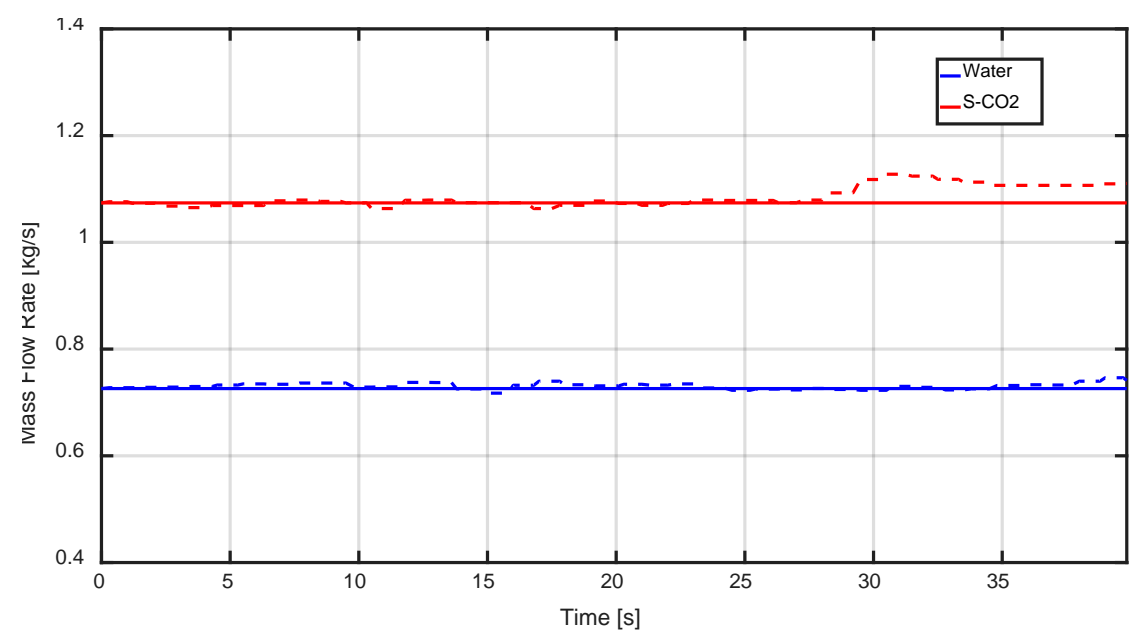

Figure 17. Model versus experiment: Mass flow rates. 


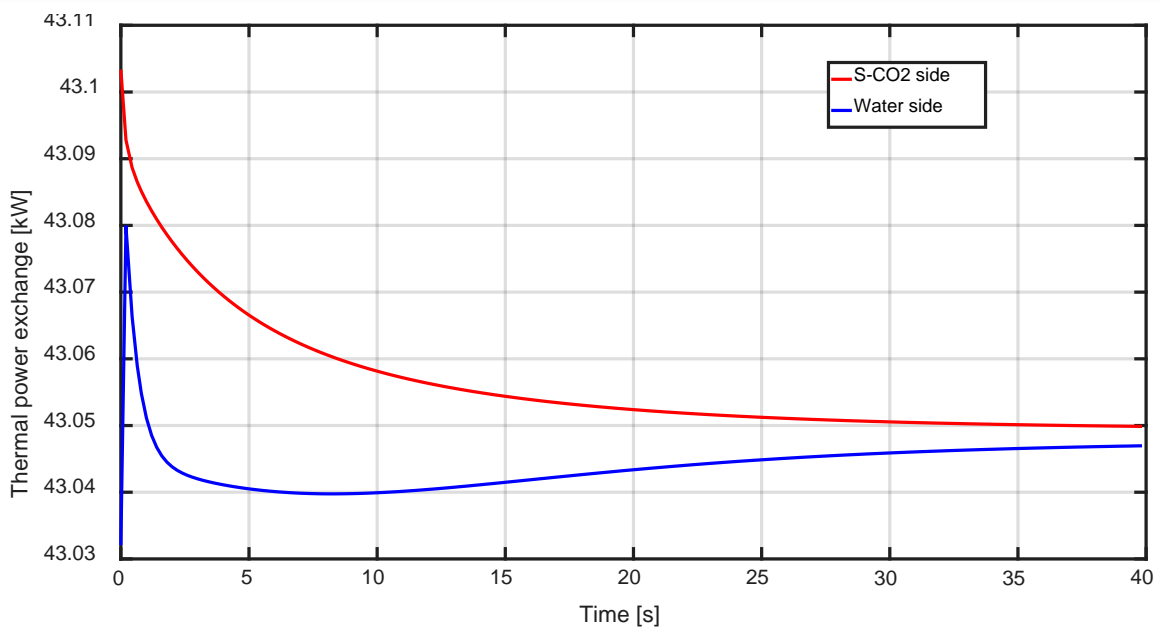

Figure 18. Thermal power exchange.

Among the variables of interest, the thermal power exchanged between the two working fluids needs to be evaluated. In Figure 18, the curves showing the thermal power disposed by the S-CO 2 side (red curve) and the thermal power absorbed by the water side (blue curve) are represented. The final converging trends of the two curves confirm the validity of the operating point as reference steady-state condition.

\subsection{Dynamic scenario}

Having assessed the model by simulating the system steady-state conditions and comparing to experiment, the transient scenario is simulated. A time window in the experiment data was selected for evaluation of the performance of the model. The window was chosen for a time interval where the system behavior is representative of kind of operational transients experienced by the PCHE. In particular, as mentioned in the Introduction, the PCHE is expected to cool down the $\mathrm{S}-\mathrm{CO}_{2}$ temperature by maintaining it just above the critical point. Since this model is expected to constitute a reliable tool to design a PCHE regulator which should prevent the working fluid from dropping below the critical point, only the portion of transient where the working fluid conditions are supercritical was studied (between 3200 and 4000 seconds).

To evaluate the quality of the model with respect to system time constants, it is necessary to simulate a fast transient initiated by perturbing the PCHE boundary conditions. As shown in Figure 19 , the water flow rate is first perturbed by imposing a small-amplitude step-wise increase at 3500 seconds and then it drops from the initial value to 0 at 3900 seconds. Similarly, the $\mathrm{S}-\mathrm{CO}_{2}$ flow rate drops from the initial value to 0 right after 3800 seconds. From Figure 19 to Figure 22, the comparison of the simulation outcomes (solid lines) with the experimental data (dash lines) is shown. Because of the abrupt flow rate variations in the experiment between 3850 and 3900 seconds, the imposed boundary condition there was modified with respect to the actual experimental data. In particular, the $\mathrm{S}-\mathrm{CO}_{2}$ and water flow rates were held just short of going to zero to avoid convergence problems. This is seen in Figure 19 in the 3850 to 4000 second interval. 


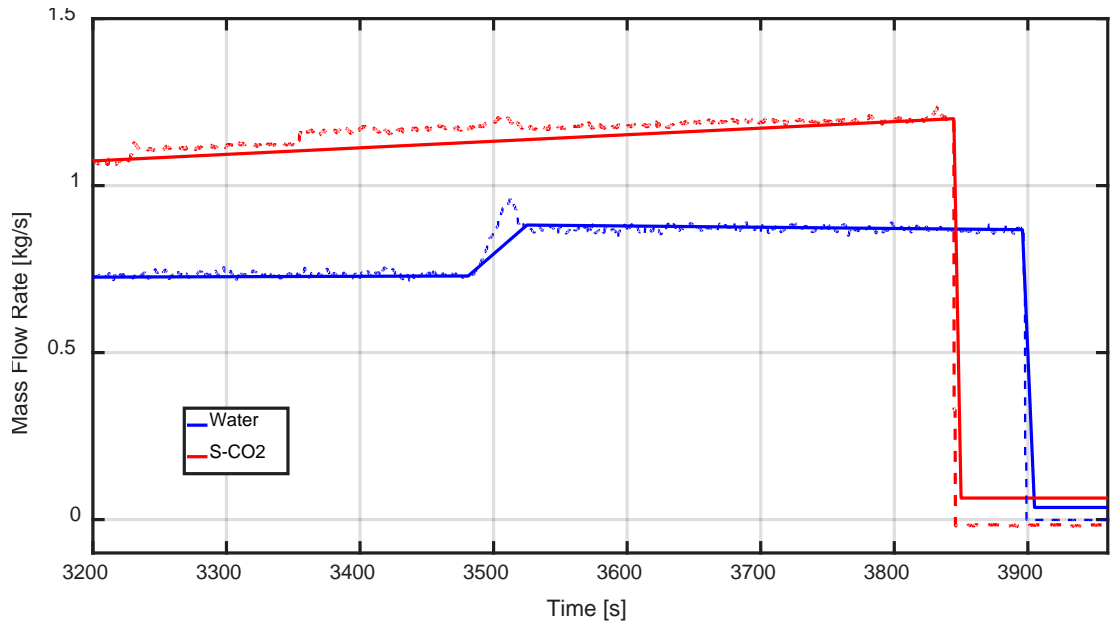

Figure 19. Evolution of S- $\mathrm{CO}_{2}$ and water flow rates at the PCHE inlet and outlet.

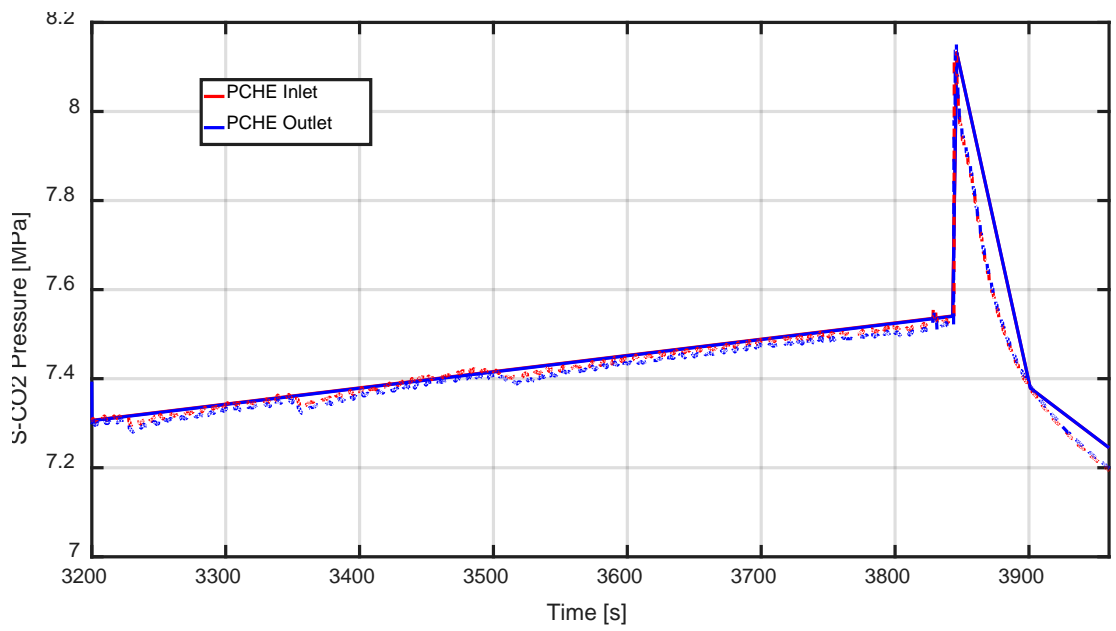

Figure 20. Evolution of S-CO $\mathrm{CO}_{2}$ pressures at the PCHE inlet and outlet.

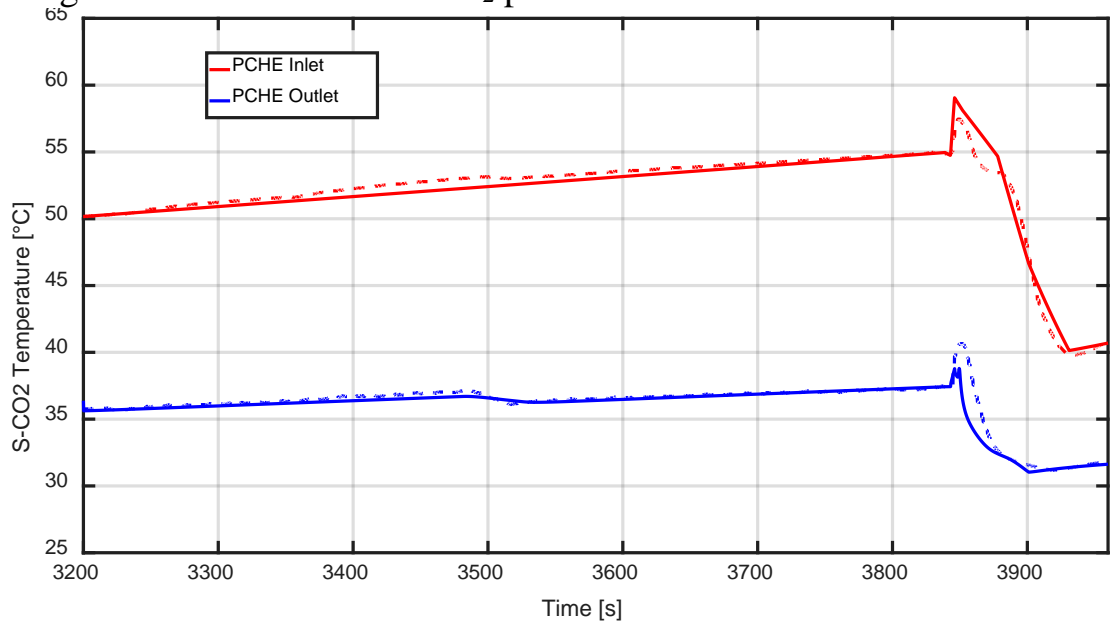

Figure 21. Evolution of S- $\mathrm{CO}_{2}$ temperatures at the PCHE inlet and outlet. 


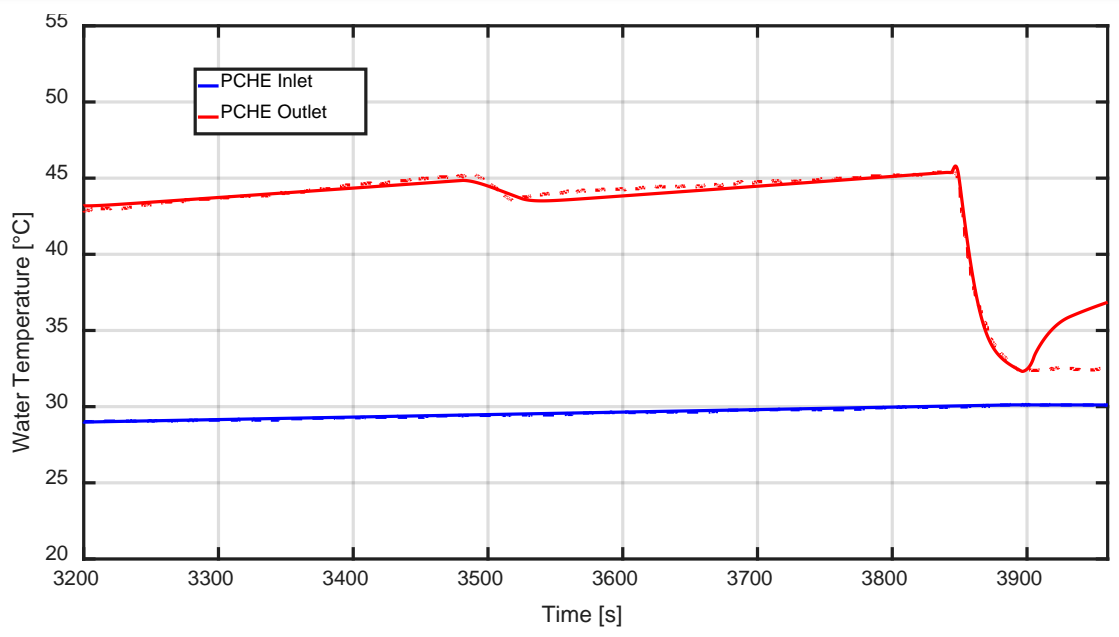

Figure 22. Evolution of water temperatures at the PCHE inlet and outlet.

These simulation outcomes indicate that the PCHE model responses for the $\mathrm{S}-\mathrm{CO}_{2}$ and the water outlet temperature are characterized by time constants that are very similar to the ones evident in the experiment data. Thus, the GPASS model is considered acceptable for advancing to the next step, controller design. This will take place in the next fiscal year.

\section{Conclusions}

A one-dimensional control-oriented model of the PCHE was developed using the General Plant Analyzer and System Simulator (GPASS) code. This modeling capability was used this fiscal year to analyze experiment data obtained from the heat exchanger in the SNL recompression Brayton cycle. The analysis indicated that the error in the water flowrate measurement was greater than required for achieving precise control of heat removal rate. Accordingly, a new water flowmeter was installed, significantly improving the quality of the measurement. Comparison of heat exchanger measurements in subsequent experiments with code simulations yielded good agreement establishing a reliable basis for the use of the GPASS PCHE model for future development of a model-based feedback controller. As for the next steps, the modeling of the heat transfer process in PCHE will be improved. In particular, realistic correlations for evaluating the heat transfer and the pressure drop for zigzagged channels in PCHEs will be implemented.

\section{References}

[1] V. Dostal, “A Supercritical Carbon Dioxide Cycle for Next Generation Nuclear Reactors”, PhD dissertation, Massachusets Institute of Technology, 2004.

[2] A. Heifetz, R.B. Vilim, Argonne National Laboratory, unpublished information, 2014.

[3] N.A. Carstens, "Control Strategies for Supercritical Carbon Dioxide Power Conversion Systems”, PhD thesis, Massachusetts Institute of Technology, 2007.

[4] R.B. Vilim, Argonne National Laboratory, unpublished information, 2013.

[5] V. Dostal, “A Supercritical Carbon Dioxide Cycle for Next Generation Reactors”, MIT Department of Nuclear Science and Engineering PhD Thesis, January 2004. 
[6] V. Gnielinski, "New Equations for heat and mass transfer in turbulent pipe and channel flow”, International Chemical Engineering, 16, April 1976.

[7] J.E. Hesselgreaves, R. Law, D. Reay "Compact Heat Exchangers: Selection, Design, and Operation”, Pergamon, $1^{\text {st }}$ Edition, 2016.

[8] R. Shah, M. Bhatti, "Handbook of Single-Phase Convective Heat Transfer", Wiley, New York, 1987.

[9] A. Moisseytsev, J.J. Sienicki, D.H. Cho, M. R. Thomas, "Comparison of Heat Exchanger Modeling with Data from $\mathrm{CO}_{2}$-to- $\mathrm{CO}_{2}$ Printed Circuit Heat Exchanger Performance Tests", Proceedings of ICAPP '10, San Diego, USA, June 13-17, 2010. 
Argonne 
Argonne National Laboratory is a U.S. Department of Energy laboratory managed by UChicago Argonne, LLC

\section{Nuclear Engineering Division}

Argonne National Laboratory

9700 South Cass Avenue, Bldg. 208

Argonne, IL 60439

www.anl.gov 